\title{
The Impact of Vitamin D Deficiency on Retinopathy and Hearing Loss among Type 2 Diabetic Patients
}

\author{
Abdulbari Bener $\left(\mathbb{D},{ }^{1,2,3}\right.$ Mustafa Eliaçık, ${ }^{4}$ Hakan Cincik $\left(\mathbb{D},{ }^{5}\right.$ Mustafa Öztürk, ${ }^{3}$ \\ Ralph A. DeFronzo, ${ }^{6}$ and Muhammad Abdul-Ghani ${ }^{6,7}$ \\ ${ }^{1}$ Department of Biostatistics \& Medical Informatics, Cerrahpaşa Faculty of Medicine, Istanbul University, Istanbul, Turkey \\ ${ }^{2}$ Department of Evidence for Population Health Unit, School of Epidemiology and Health Sciences, \\ The University of Manchester, Manchester, UK \\ ${ }^{3}$ Department of Endocrinology, Medipol International School of Medicine, Istanbul Medipol University, Istanbul, Turkey \\ ${ }^{4}$ Department of Ophthalmology, Medipol International School of Medicine, Istanbul Medipol University, Istanbul, Turkey \\ ${ }^{5}$ Department of ENT and Audiology, Medipol International School of Medicine, Istanbul Medipol University, Istanbul, Turkey \\ ${ }^{6}$ Division of Diabetes, University of Texas Health Science Center at San Antonio, 7703 Floyd Curl Drive, San Antonio, TX 78229, USA \\ ${ }^{7}$ Academic Health System, Hamad General Hospital, Doha, Qatar
}

Correspondence should be addressed to Abdulbari Bener; abdulbari.bener@istanbul.edu.tr

Received 7 February 2018; Accepted 7 June 2018; Published 9 July 2018

Academic Editor: Peyman Björklund

Copyright (@ 2018 Abdulbari Bener et al. This is an open access article distributed under the Creative Commons Attribution License, which permits unrestricted use, distribution, and reproduction in any medium, provided the original work is properly cited.

\begin{abstract}
Aim. The current study was aiming to investigate the relation between vitamin $\mathrm{D}$, retinopathy, and hearing loss among type 2 diabetes mellitus (T2DM) patients. Methods. Cross-sectional study carried on 638 subjects aged between 20 and 60 years who visited the Endocrinology, Ophthalmology, and ENT Outpatient Clinics of the Medipol Hospital during the period from March 2016 to May 2017. Two audiometers Grason Stadler GSI 61 and Interacoustics AC40 Clinical audiometer were used to evaluate the hearing loss. Risk factors for diabetic retinopathy were evaluated, including age, sex, diabetes duration, glycated hemoglobin (HbAlc), hypertension, and lipid profiles. Results. The mean age ( \pm SD, in years) for retinopathy with hearing loss versus normal subjects was $47.7 \pm 10.2$ versus $48.5 \pm 9.1$. The associated risk factors were significantly higher in T2DM with hearing loss, hypertension ( $32.6 \%$ versus $15.7 \%$ ), tinnitus ( $40.0 \%$ versus $18.0 \%)$, vertigo $(59.7 \%$ versus $26.8 \%)$, and headache (54.9\% versus $45.3 \%$ ), than in normal hearing diabetes. There were statistically significant differences between hearing impairment versus normal hearing for vitamin $\mathrm{D}[19.40 \pm 9.71 \mathrm{ng} / \mathrm{ml}$ versus $22.67 \pm 9.28 \mathrm{ng} / \mathrm{ml} ; \mathrm{p}<0.001]$, calcium, magnesium, phosphorous, cholesterol, HDL-C, LDL-C, albumin, systolic blood pressure [131.70 $\pm 9.25 \mathrm{Hg}$ versus $127.73 \pm 11.98 \mathrm{Hg}$ ], diastolic blood pressure [82.20 $\pm 8.60 \mathrm{~mm} \mathrm{Hg}$ versus $79.80 \pm 8.20 \mathrm{~mm} \mathrm{Hg}$ ], and microalbuminuria. Multivariate logistic regression analysis revealed that variables such as vertigo, duration of DM, mobile/I pad phone, vitamin D deficiency, sleeping disturbance, headache, frequently TV watching, tinnitus, cigarette smokers, and hypertension were considered at higher risk as a predictors of retinopathy with hearing loss among diabetic patients. Conclusion. Vitamin D deficiency is considered as a risk factor for diabetic retinopathy and hearing loss among diabetic patients. Meanwhile, hyperglycemia could be considered as a modifiable risk factor for diabetic retinopathy; tight glycemic control may be the most effective and important therapy for improving quality of life and substantially reducing the incidence of retinopathy and in T2DM patients.
\end{abstract}

\section{Introduction}

Type 2 diabetes mellitus (T2DM) is a major health problem associated with significant morbidity, mortality, and healthcare expenditure. The etiology of T2DM is complex and includes abnormalities in multiple organs, including liver, skeletal muscle, adipocytes, gut, and beta cell $[1,2]$. T2DM also is a major risk factor for cardiovascular disease $[3,4]$ which is the leading cause of death in western countries $[5,6]$. Several modifiable lifestyle factors, e.g., sleep duration, physical activity, and healthy-balanced diet can reduce the incidence of T2DM among high risk individuals $[4,5]$. The 
prevalence of T2DM is even more widespread in the Middle East and its impact on public health is greater than other regions of the world $[1,2]$. According to a populationbased study in Turkey, the prevalence of diabetic retinopathy was $12.8 \%$ among type 2 diabetic patients [4]. Diabetic retinopathy has a complex process [4-6].

Recent studies have reported that vitamin D deficiency is closely related to obesity and increased risk of T2DM [612]. There are very strong correlations between vitamin $D$ status, obesity, and T2DM [5-7, 12-14]. Similarly, several authors found that vitamin $\mathrm{D}$ deficiency is a predisposing factor for developing diabetes and increasing hearing loss [6-15]. Vitamin D insufficiency is very common worldwide. Different epidemiological studies have reported that more than $40 \%$ of adult populations are at risk of vitamin D insufficiency [5]. Further, vitamin D deficiency may play a role in the pathogenesis of diabetic retinopathy $[6,7,13,16]$. Thus, it is not surprising that hearing loss if often found in T2DM patients $[6,7,12,14-17]$. A number of studies have attempted to identify the cause of hearing loss in T2DM [611,13 ] and found hyperglycemia to be an important risk factor. Because hyperglycemia is the principal risk factor for diabetic microvascular complications, i.e., retinopathy, neuropathy, and nephropathy $[5-7,14]$, we hypothesize that a strong correlation between hearing loss and diabetic retinopathy will be present in T2DM patients $[3,6,8,9,16]$. Because low level of vitamin $\mathrm{D}$ was also related to increased risk of hearing loss and retinopathy, we also hypothesized that T2DM subjects who manifest hearing impairment and retinopathy may also have low plasma vitamin D levels $[5-7,13]$. The aim of this study was to investigate the relationship between vitamin $\mathrm{D}$, retinopathy, and hearing loss among T2DM.

\section{Subjects and Methods}

This is a cross-sectional study conducted on patients aged from 20 and 60 years who visited the Endocrinology, Ophthalmology, and ENT Outpatient Clinics of the Medipol Hospital during the period from March 2016 to May 2017. IRB ethical approval for this study was obtained from the Medipol International School of Medicine, Istanbul Medipol University, and informed written consent was obtained from patients before the start of the study.

The present sample was based on the representative registered 900 patients with diagnosed diabetes. Of the 900 approached registered patient with T2DM, 638 (70.9\%) agreed to participate in this study at the Medipol International School of Medicine, Istanbul Medipol University.

2.1. Laboratory Measurements. The patients were considered to have DM if they have a history of DM and are currently taking oral medications for diabetes; we have followed the methods described by Bener et al. 2017 [1]; American Diabetes Association [3] and International Diabetes Federation (IDF) [2]; Bener et al. [1, 6]. Meanwhile, DM has been defined when fasting venous blood glucose concentration is equal to or higher than $7.0 \mathrm{mmol} / \mathrm{L}$ and/or for a 2-hour postglucose tolerance test (GTT); venous blood glucose concentration is higher than $11.1 \mathrm{mmol} / \mathrm{L}$. Oral glucose tolerance test (OGTT) was carried out only if blood sugar was less than $7 \mathrm{mmol} / \mathrm{l}$. The inclusion criteria are comprised of diagnosis of T2DM according to IDF criteria international standards by WHO and IDF $[2,3]$, fasting plasma glucose (FPG) higher than $7.0 \mathrm{mmol} / \mathrm{L}$ and/or 2-hour postprandial plasma glucose (PPG), or random plasma glucose higher than $11.1 \mathrm{mmol} / \mathrm{L}$ [5]. Furthermore, having regular antidiabetic drug treatment for at least 3 years, aged between 20 and 60 years, residence in a city of Istanbul for more than 3-year period.

The study included sociodemographic characteristics, lifestyle habits, BMI, comorbid symptoms, diabetic complications, systolic and diastolic blood pressures, clinical biochemistry serum triglyceride, total cholesterol, high-density lipoprotein (HDL-C) cholesterol, low density lipoprotein (LDL-C) cholesterol, hemoglobin Alc (HbAlc), and fasting glucose levels (FPG) which were collected. Hypertension criteria are defined according to the World Health Organization (WHO) [18] where systolic blood pressure $(\mathrm{SBp}) \geq$ $140 \mathrm{mmHg}$ or Diastolic Blood Pressure (DBp) $\geq 90 \mathrm{mmHg}$ or using antihypertensive medication [18].

2.1.1. Ophthalmic Assessment Method. All the patients with diabetes underwent a complete ophthalmic examination comprised of best-corrected visual acuity, indirect ophthalmoscopy, slit-lamp biomicroscopy, and fundus fluorescein angiography. ETDRS (Early Treatment Diabetic Retinopathy Study) [1] adaptation of the modified Airlie House classification system was used for diabetic retinopathy grading and diabetic retinopathy was further categorized as nonproliferative diabetic retinopathy (NPDR) and proliferative diabetic retinopathy (PDR). The ophthalmologist at the reference center inspected the downloaded digital images, evaluated them for the presence or absence of diabetic retinopathy, and graded the retinopathy using a modified version of the Airlie House classification [19].

2.1.2. Hearing Assessment Method. Pure tone audiometry is a behavioral test used to measure hearing sensitivity. This measure involves the peripheral and central auditory systems $[5,15,20]$. Two clinical digital audiometers (Garson Stadler GSI 61 and Interacoustics AC40 Clinical Audiometer, Interacoustics, Assens, Denmark) are used to be a device for diagnosing hearing loss that are regularly calibrated to international standards which were performed by pretrained technicians to test patients' hearing level. Pure tone audiometry was measured at $0.25,0.5,1,2,4$, and $8 \mathrm{kHz}$ to detect the hearing threshold at each given frequency in a soundisolated room, standardized according to the manufacturer's instructions. Pure tone average (PTA) was determined, based on the air-conduction average threshold levels in each ear (in decibels) at $0.5,1,2$, and $4 \mathrm{kHz}$. This pure tone average is an indication of how well a patient can hear a normal conversation. Patients without hearing loss would have a 0 to $26 \mathrm{~dB}$ loss. Hearing loss evaluation is described as follows $[5,15,20]$ : normal $(\leq 26 \mathrm{~dB})$ and $26 \mathrm{~dB}$ above, hearing loss.

The statistical analysis was performed by using the Statistical Package for Social Sciences [SPSS]. Student's t-test was used to ascertain the significance of differences between 
mean values of two continuous variables and confirmed by the nonparametric Mann-Whitney tests to determine if the results differed, indicating lack of normal distribution of the variable. Chi-square test Fisher's exact test (two-tailed) were used to test significance differences between two or more categorical groups. A multivariate logistic regression model was performed to assess the relation between selected lifestyle factors, retinopathy, and presence of hearing loss. Confounders were assessed statistically through change in beta coefficient (crude $\beta$-adjusted $\beta$ ), and if the change was more than $10 \%$, the variable was considered as a confounder and retained in the final model. The cut-off value for significance was chosen as 0.05 .

\section{Results}

Table 1 presents the sociodemographic characteristics of subjects with hearing impairment and subjects with normal hearing. Majority of the hearing loss was observed at the age above 45 years of age. More than $90 \%$ of the studied patients were frequent users of mobile phones and approximately $88 \%$ of subjects with hearing loss were watching TV. The mean duration of diabetes was $9.54 \pm 5.31$ years, duration of sleep was $5.88 \pm 1.25$ hours, and $27.8 \%$ had positive family history of diabetes. Subjects with hearing impairment had worst risk factor profile than T2DM patients with normal hearing: hypertension, (23\% versus $14.8 \%$ ), tinnitus $(33.3 \%$ versus $21.1 \%$ ), vertigo ( $25.4 \%$ versus $16.6 \%)$, and headache (54.0\% versus $42.0 \%)$, respectively (Table 1 ).

Table 2 presents the metabolic characteristics of the two groups. Vitamin D levels were significantly lower in subjects with hearing impairment compared to subjects with normal hearing $[19.40 \pm 0.71 \mathrm{ng} / \mathrm{ml}$ versus $22.65 \pm 9.280 \mathrm{ng} / \mathrm{ml}$; respectively, $\mathrm{p}<0.001]$. Other parameters were calcium [2.18 $\pm 0.38 \mathrm{ng} / \mathrm{ml}$ versus $2.39 \pm 0.26 \mathrm{mmol} / \mathrm{L} ; \mathrm{p}<0.001]$, magnesium $[0.76 \pm 0.10 \mathrm{mmol} / \mathrm{L}$ versus $0.90 \pm 0.09 \mathrm{mmol} / \mathrm{L} ; \mathrm{p}<$ $0.001]$, phosphorous $[1.40 \pm 0.32 \mathrm{mmol} / \mathrm{L}$ versus $1.58 \pm$ $0.29 \mathrm{mmol} / \mathrm{L} ; \quad \mathrm{p}<0.001]$, creatinine $[68.74 \pm 14.47 \mathrm{mmol} / \mathrm{L}$

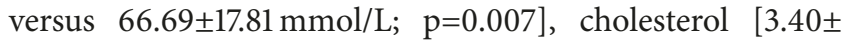
$0.66 \mathrm{mmol} / \mathrm{L}$ versus $3.16 \pm 0.80 \mathrm{mmol} / \mathrm{L} ; \mathrm{p}=0.020]$, $\mathrm{HDL}(1.45 \pm$ $0.90 \mathrm{mmol} / \mathrm{L}$ versus $1.22 \pm 0.37 \mathrm{mmol} / \mathrm{L} ; \mathrm{p}=0.001]$, LDL [1.97 \pm $0.92 \mathrm{mmol} / \mathrm{L}$ versus $1.72 \pm 0.69 \mathrm{mmol} / \mathrm{L} ; \mathrm{p}=0.025$ ], albumin [40.10 $\pm 4.41 \mathrm{mmol} / \mathrm{L}$ versus $38.68 \pm 4.09 \mathrm{mmol} / \mathrm{L} ; \mathrm{p}=0.001]$, systolic blood pressure [131.70 $\pm 9.25 \mathrm{mmHg}$ versus $127.73 \pm$

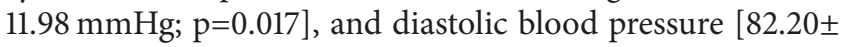
$8.60 \mathrm{mmHg}$ versus $79.80 \pm 8.20 \mathrm{mmHg} ; \mathrm{p}=0.004]$ and microalbuminuria $[14.59 \pm 2.49 \mathrm{mmol} / \mathrm{L}$ versus $9.07 \pm 3.50 \mathrm{mmol} / \mathrm{L}$ $\mathrm{p}<0.001]$.

Table 3 presents the mean distribution of Pure Tone Thresholds for both groups, with retinopathy and hearing loss and without retinopathy and normal hearing. There were highly statistically significant differences between right and left ear frequency in $\mathrm{dB}$ unit $(\mathrm{p}<0.001)$. The mean and St. Dev of PTA in the right ear for retinopathy with hearing impairment was $33.21 \pm 14.55 \mathrm{~dB}$, compared to $19.34 \pm 10.42 \mathrm{~dB}$ in the nonretinopathy with normal hearing. The mean and St. Dev of PTA in the left ear for retinopathy with hearing impairment was $32.07 \pm 10.11 \mathrm{~dB}$ compared to $19.07 \pm 12.7 \mathrm{~dB}$ in nonretinopathy with normal hearing. Differences in speech reception threshold [SRT] between the two groups were also significant in both the right and left ear $(\mathrm{p}<0.001)$. Also, the speech discrimination score [SDS] as nonretinopathy with normal hearing had better SDS than the retinopathy with hearing impairment; the differences were highly significant for either the right or left ears $(\mathrm{p}<0.001)$.

Meanwhile, in present study, we have identified a significant strong correlation coefficient between diabetic retinopathy and SBp $(\mathrm{r}=0.439, \mathrm{p}=0<0.01) \mathrm{DBp}(\mathrm{r}=0.226, \mathrm{p}=0<0.01)$, HbAlc $(r=0.446, p=0<0.01)$, BMI $(r=0.233, p=0<0.01)$, and physical activity $(\mathrm{r}=0.126, \mathrm{p}=0<0.05)$.

Table 4 presents multivariable logistic regression analysis of variables for predictors of hearing loss with neuropathy among diabetic patients. Vertigo (OR 4.09 95\% CI 1.799.66; $\mathrm{p}<0.001$ ), duration of DM (OR 1.92 95\%CI 1.70-2.44; $\mathrm{p}<0.001$ ), mobile/I pad phone (OR 4.25 95\% CI 2.85-9.97; $\mathrm{p}<0.001$ ), vitamin D deficiency (OR 2.03; 95\%CI 1.94-3.06, $\mathrm{p}=0.002$ ), sleeping disturbance (OR 2.68; 95\%CI 2.24-3.58, $\mathrm{p}=0.004$ ), headache (OR 2.39 95\%CI 1.30-4.32; $\mathrm{p}=0.005$ ), frequently TV watching (OR 2.42 95\%CI 1.26-4.00; $\mathrm{p}=0.006$ ), tinnitus (OR 1.95 95\%CI (1.22-3.13); $\mathrm{p}=0.007$ ), cigarette smokers (OR 1.79; 95\%CI 1.26-3.23, $\mathrm{p}=0.029$ ), and hypertension (OR 1.71 95\%CI 1.36-2.82); $\mathrm{p}=0.036$ ) were considered at higher risk as a predictors of retinopathy with hearing loss among diabetic patients.

\section{Discussion}

The results of the present study have revealed high prevalence of hearing impairment in association with retinopathy in T2DM patients. The association between diabetes and eye disease is well recognized with diabetic retinopathy as the most common eye disease in subjects with T2DM [9]. However, the link between diabetes and hearing loss has not been universally accepted until recently. The first positive correlation was found in 1961 by Jorgensen and Bush [20] which showed that subjects with proliferative diabetic retinopathy were twice as likely to have hearing loss. However, more recent studies agree that diabetes is correlated with high-frequency hearing loss [9].

More recently, Bener et al. [5, 6] studied 1,633 diabetic patients and reported that an overall prevalence of peripheral neuropathy was $9.5 \%$ among them. The analysis showed that the condition was significantly associated with age, male gender, consanguinity, family history of DM, and elevated blood pressure. More recently from a study by Ooley et al. [9] after controlling for glucose control, as measured by HbAlc and renal function measured with serum creatinine, the presence of diabetic retinopathy was significantly associated with the severity of hearing loss in both ears (right ear, $\mathrm{P}=$ .018 and left ear, $\mathrm{P}=.007$ ). Usually, the chronic hyperglycemia in diabetic patients could affect hearing leading to hearing impairment. Several studies have reported close association between hearing impairment and DM $(3,9,12)$. Furthermore, more recently Bener et al. [1] and Ooley et. all [9] reported that HbAlc level was associated with hearing impairment in nondiabetic participants, and higher HbAlc levels could be used as an indicator for the presence of hearing loss. A 
TABLE 1: Comparison of sociodemographic and clinical characteristics between diabetic retinopathy patients with and without hearing loss (N=638).

\begin{tabular}{|c|c|c|c|c|}
\hline Variables & $\begin{array}{c}\text { Retinopathy with } \\
\text { Hearing Loss } \\
\geq 26 \mathrm{~dB} \text { n=126 }\end{array}$ & $\begin{array}{c}\text { Non-Retinopathy } \\
\text { Normal Hearing } \\
<26 \mathrm{~dB} n=512 \\
\end{array}$ & Odds Ratio 95\%CI & P value \\
\hline \multicolumn{5}{|l|}{ Age groups (in years): } \\
\hline$<40$ & $21(16.7)$ & $160(31.2)$ & 1 & \\
\hline $40-49$ & $32(25.4)$ & $115(22.5)$ & $2.12(1.16-3.86)$ & 0.014 \\
\hline $50-59$ & $24(19.0)$ & $122(23.8)$ & $1.50(0.79-2.81)$ & 0.208 \\
\hline 60 and above & $49(38.9)$ & $115(22.5)$ & $3.24(1.18-4.08)$ & $<0.001$ \\
\hline \multicolumn{5}{|l|}{ Gender: } \\
\hline Male & $54(42.9)$ & $178(34.8)$ & $1.50(0.94-2.09)$ & 0.091 \\
\hline Female & $72(57.1)$ & $334(65.2)$ & 1 & \\
\hline \multicolumn{5}{|l|}{ Level of education: } \\
\hline Intermediate & $56(44.4)$ & $183(23.8)$ & $1.50(1.00-2.47)$ & 0.050 \\
\hline Secondary & $31(24.6)$ & $129(26.4)$ & $1.23(0.73-2.07)$ & 0.431 \\
\hline University & $39(31.0)$ & $200(37.6)$ & 1 & \\
\hline \multicolumn{5}{|l|}{ BMI $\left(\mathrm{kg} / \mathrm{m}^{2}\right):$} \\
\hline $\operatorname{Normal}\left(<25 \mathrm{~kg} / \mathrm{m}^{2}\right)$ & $33(26.2)$ & $138(27.0)$ & 1 & \\
\hline Overweight $25-30 \mathrm{~kg} / \mathrm{m}^{2}$ & $52(41.3)$ & $238(46.50)$ & $0.91(0.56-1.48)$ & 0.714 \\
\hline Obese $>30 \mathrm{~kg} / \mathrm{m}^{2}$ & $41(32.5)$ & $136(26.6)$ & $1.26(0.75-2.11)$ & 0.378 \\
\hline \multicolumn{5}{|l|}{ Physical activity: } \\
\hline More than $30 \mathrm{~min} /$ day & $38(30.2)$ & $144(28.1)$ & 1 & \\
\hline Less than $30 \mathrm{~min} /$ day & $88(69.8)$ & $368(71.9)$ & $0.90(0.59-1.38)$ & 0.650 \\
\hline \multicolumn{5}{|l|}{ Fast food habits: } \\
\hline Yes & $31(24.6)$ & $76(14.8)$ & $1.50(0.94-2.41)$ & 0.009 \\
\hline No & $95(75.4)$ & $436(75.2)$ & 1 & \\
\hline \multicolumn{5}{|l|}{ Cigarette Smoking status: } \\
\hline Yes & $27(21.4)$ & $69(13.5)$ & $1.75(1.16-2.87)$ & 0.026 \\
\hline No & $99(78.6)$ & $443(86.5)$ & 1 & \\
\hline \multicolumn{5}{|l|}{ Do you use mobile phone } \\
\hline Yes & $130(90.3)$ & $423(81.8)$ & $1.95(1.08-3.54)$ & 0.027 \\
\hline No & 14(9.7) & $89(18.2)$ & & \\
\hline \multicolumn{5}{|l|}{ Can you watch/hear TV: } \\
\hline Yes & $111(88.1)$ & $394(77.0)$ & $2.21(1.24-3.94)$ & 0.006 \\
\hline No & 15(11.9) & $118(23.0)$ & 1 & \\
\hline \multicolumn{5}{|l|}{ Family history of DM: } \\
\hline Yes & $35(27.8)$ & $83(16.2)$ & $1.98(1.26-3.13)$ & 0.003 \\
\hline No & $91(71.2)$ & $429(83.8)$ & 1 & \\
\hline \multicolumn{5}{|l|}{ Hypertension } \\
\hline Yes & $29(23.0)$ & $76(14.8)$ & $1.71(1.10-2.77)$ & 0.028 \\
\hline No & $97(77.0)$ & $436(85.2)$ & 1 & \\
\hline \multicolumn{5}{|l|}{ Tinnitus } \\
\hline Yes & $42(33.3)$ & $108(21.1)$ & $1.87(1.22-2.87)$ & 0.004 \\
\hline No & $84(66.7)$ & $404(78.9)$ & 1 & \\
\hline \multicolumn{5}{|l|}{ Vertigo } \\
\hline Yes & $32(25.4)$ & $85(16.6)$ & $1.71(1.08-2.71)$ & 0.023 \\
\hline No & $94(74.6)$ & $427(83.4)$ & 1 & \\
\hline \multicolumn{5}{|l|}{ Headache } \\
\hline Yes & $68(54.0)$ & $215(42.0)$ & $1.61(1.09-2.40)$ & 0.044 \\
\hline No & $58(46.0)$ & $297(58.0)$ & 1 & \\
\hline Duration of diabetes (years) & $9.54 \pm 5.31$ & $8.19 \pm 4.42$ & $1.64(1.14-2.36)$ & 0.028 \\
\hline Sleeping (in hrs) & $5.88 \pm 1.25$ & $6.39 \pm 1.24$ & $2.93(1.96-4.45)$ & 0.001 \\
\hline
\end{tabular}


TABLE 2: Clinical biochemistry baseline value among retinopathy hearing loss and normal hearing subject among $\mathrm{T} 2 \mathrm{DM}$ patients $(\mathrm{N}=638)$.

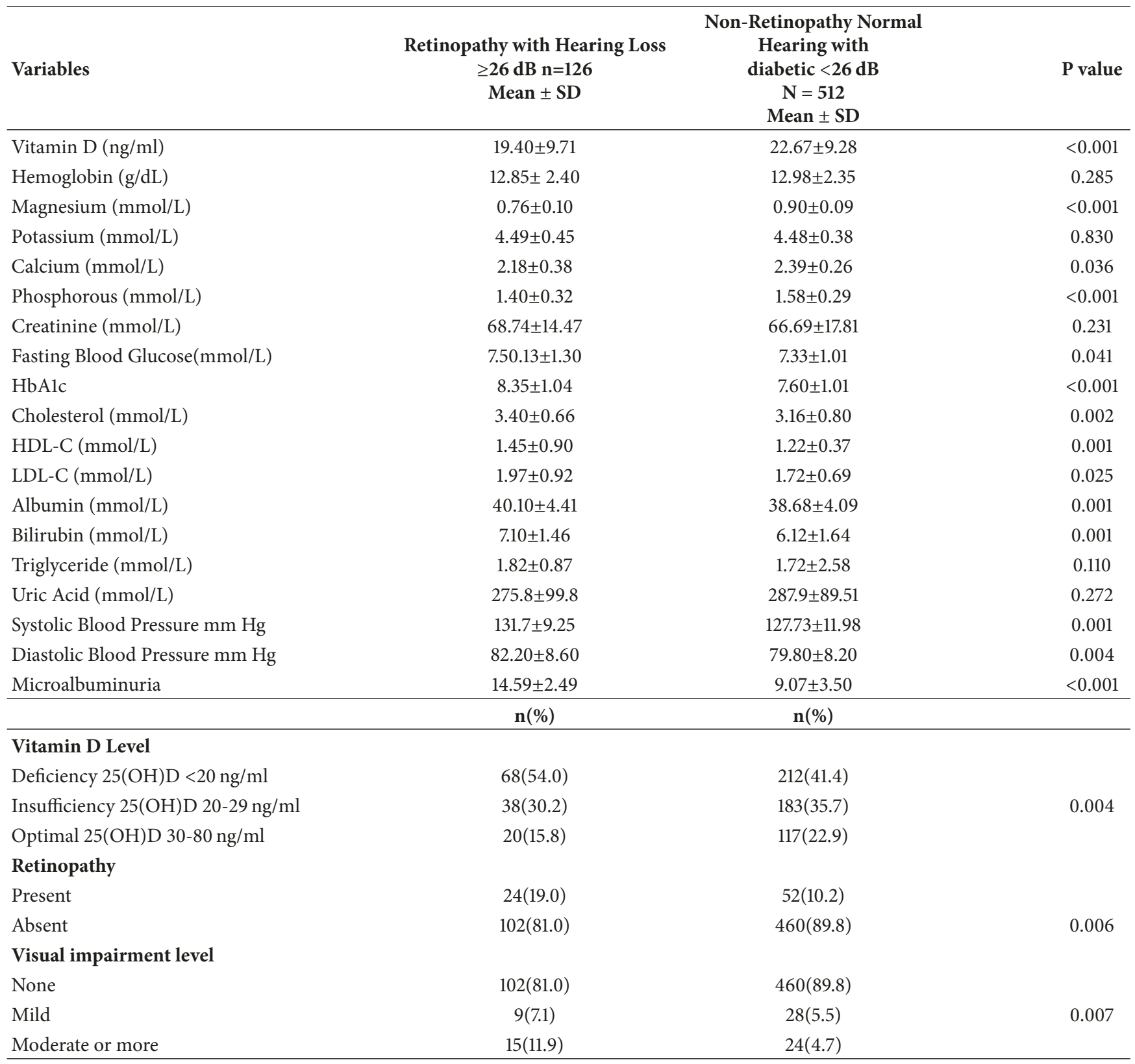

recent meta-analysis concluded that mild hearing loss is more prevalent in participants with DM [11].

The current study results are consistent with previous reports about the close relationship between T2DM and high-frequency sensorineural hearing loss [1, 8-12, 20, 21] and impaired auditory brainstem responses $[7,10]$. These results are in support of the fact that diabetes mellitus may have very complex repercussion on the auditory pathways. The correlation between hearing loss and hypertension can be considered as an important risk factors. Most previous studies reported that hypertension was associated with highfrequency hearing impairment, and likewise, in this study, we found a positive association between these variables $[6,9,20$, 21].
More recent study by Praidou et al. [22] reported reduced total physical activity in patients with severe to very severe nonproliferative diabetic retinopathy and proliferative diabetic retinopathy compared to patients with mild to moderate nonproliferative diabetic retinopathy and to control group. Also, the current study showed the a significant strong association between diabetic retinopathy and some risk factors such as SBp, DBp, HbAlc, BMI, and physical activity. Furthermore, our results also are in an agreement with previous suggestion more recently by Bener et al. [1] and Praidou et al. [22] about the correlation between HbAlc levels, physical activity, BMI, and diabetic retinopathy.

The current study reveals strong association between high prevalence of hearing impairment, vertigo, and tinnitus in 
TABLE 3: Mean pure tone thresholds for hearing loss and normal hearing among diabetes subjects $(\mathrm{N}=638)$.

\begin{tabular}{|c|c|c|c|c|}
\hline Variables & & $\begin{array}{c}\text { Retinopathy with } \\
\text { Hearing Loss } \\
\geq 26 \mathrm{~dB} \\
n=126 \\
\text { Mean } \pm \text { SD }\end{array}$ & $\begin{array}{c}\text { Non-Retinopathy } \\
\text { Normal Hearing with } \\
\text { diabetic }<26 \mathrm{~dB} \\
\mathrm{~N}=512 \\
\text { Mean } \pm \mathrm{SD}\end{array}$ & p-value significance \\
\hline \multicolumn{5}{|c|}{ Frequency Side } \\
\hline $250 \mathrm{~Hz}$ & $\mathrm{Ri}$ & $27.03 \pm 15.57$ & $22.96 \pm 7.22$ & $<0.001$ \\
\hline $250 \mathrm{~Hz}$ & Le & $32.54 \pm 16.71$ & $23.20 \pm 12.18$ & $<0.001$ \\
\hline $500 \mathrm{~Hz}$ & $\mathrm{Ri}$ & $33.85 \pm 18.32$ & $19.20 \pm 14.79$ & $<0.001$ \\
\hline $500 \mathrm{~Hz}$ & Le & $29.60 \pm 14.54$ & $18.47 \pm 12.38$ & $<0.001$ \\
\hline $1,000 \mathrm{~Hz}$ & $\mathrm{Ri}$ & $31.43 \pm 17.58$ & $16.26 \pm 9.33$ & $<0.001$ \\
\hline $1,000 \mathrm{~Hz}$ & Le & $30.67 \pm 17.26$ & $16.31 \pm 12.53$ & $<0.001$ \\
\hline $1,500 \mathrm{~Hz}$ & $\mathrm{Ri}$ & $31.90 \pm 18.5$ & $17.21 \pm 10.71$ & $<0.001$ \\
\hline $1,500 \mathrm{~Hz}$ & Le & $31.34 \pm 16.81$ & $16.68 \pm 13.24$ & $<0.001$ \\
\hline $2,000 \mathrm{~Hz}$ & $\mathrm{Ri}$ & $32.38 \pm 19.42$ & $18.17 \pm 12.10$ & $<0.001$ \\
\hline $2,000 \mathrm{~Hz}$ & Le & $32.02 \pm 16.36$ & $17.06 \pm 13.96$ & $<0.001$ \\
\hline $3,000 \mathrm{~Hz}$ & $\mathrm{Ri}$ & $33.79 \pm 20.62$ & $20.95 \pm 12.50$ & $<0.001$ \\
\hline $3,000 \mathrm{~Hz}$ & Le & $34.00 \pm 17.96$ & $20.38 \pm 15.58$ & $<0.001$ \\
\hline $4,000 \mathrm{~Hz}$ & $\mathrm{Ri}$ & $35.20 \pm 21.82$ & $23.73 \pm 12.92$ & $<0.001$ \\
\hline $4,000 \mathrm{~Hz}$ & Le & $35.99 \pm 19.56$ & $23.70 \pm 17.21$ & $<0.001$ \\
\hline $6,000 \mathrm{~Hz}$ & $\mathrm{Ri}$ & $38.97 \pm 24.83$ & $27.22 \pm 17.48$ & $<0.001$ \\
\hline $6,000 \mathrm{~Hz}$ & Le & $37.03 \pm 20.04$ & $25.35 \pm 17.29$ & $<0.001$ \\
\hline $8,000 \mathrm{~Hz}$ & $\mathrm{Ri}$ & $42.74 \pm 27.85$ & $30.71 \pm 22.05$ & $<0.001$ \\
\hline $8,000 \mathrm{~Hz}$ & Le & $38.08 \pm 20.52$ & $27.01 \pm 17.37$ & $<0.001$ \\
\hline PTA & $\mathrm{Ri}$ & $33.21 \pm 14.55$ & $19.34 \pm 10.42$ & $<0.001$ \\
\hline PTA & Le & $32.07 \pm 10.11$ & $19.07 \pm 9.89$ & $<0.001$ \\
\hline SRT & $\mathrm{Ri}$ & $35.51 \pm 18.44$ & $26.34 \pm 12.51$ & $<0.001$ \\
\hline SRT & Le & $35.87 \pm 20.81$ & $27.85 \pm 16.34$ & $<0.001$ \\
\hline SDS (\%) & $\mathrm{Ri}$ & $66.16 \pm 14.08$ & $76.00 \pm 15.67$ & $<0.001$ \\
\hline SDS (\%) & Le & $67.00 \pm 10.53$ & $75.17 \pm 15.20$ & $<0.001$ \\
\hline
\end{tabular}

PTA: pure tone average; SRT: speech reception threshold; SDS: speech discrimination score.

TABLE 4: Multivariate stepwise logistic regression analysis for predictors of hearing loss and retinopathy among $\mathrm{T} 2 \mathrm{DM}$ patients (N=638).

\begin{tabular}{lcc}
\hline Variables & Adj. OR (95\%CI) & P value \\
\hline Vertigo & $4.09(1.79-9.66)$ & $<0.001$ \\
Duration of DM & $1.92(1.70-2.44)$ & $<0.001$ \\
Mobile/I pad Phone use & $4.25(2.85-9.97)$ & $<0.001$ \\
Vitamin D deficiency & $2.03(1.94-3.06)$ & 0.002 \\
Sleep disturbance & $2.68(2.24-3.58)$ & 0.004 \\
Head ache & $2.39(1.30-4.32)$ & 0.005 \\
Frequently TV watching & $2.42(1.26-4.00)$ & 0.006 \\
Tinnitus & $1.95(1.22-3.13)$ & 0.007 \\
Cigarette Smoking (yes) & $1.79(1.26-3.23)$ & 0.029 \\
Hypertension & $1.71(1.36-2.82)$ & 0.036 \\
\hline
\end{tabular}


T2DM patients $[1,5,6]$. The results of this study demonstrated a strong correlation between glucose control as measured by $\mathrm{HbAlc}$, serum vitamin $\mathrm{D}$ levels, the degree of diabetic retinopathy, and the severity of sensorineural hearing loss which is confirmative most recently study by Bener et al. [1] with diabetic neuropathy.

The present study is not without its limitations. Firstly, this is a cross-sectional design with limits the ability to assess causality. Secondly, only one time point was recorded for the subjects in this study. Thirdly, also, there is possible selection bias as this is not a study of consecutive patients seen at our institution. Although, dietary intake and outdoor exposure data were collected. Additionally, effects from sunlight exposure were minimized in this study as all subjects were enrolled over a twelve-month period. Finally, beside several limitations, the analysis revealed that the overall mean standard deviation of 25(OH)D in this study was statistically strong significant differences between hearing impairment versus normal hearing for vitamin $\mathrm{D}[19.40 \pm 0.71 \mathrm{ng} / \mathrm{ml}$ versus $22.65 \pm 9.280 \mathrm{ng} / \mathrm{ml} ; \mathrm{p}<0.001]$.

\section{Conclusion}

The current study results suggests a strong positive association between vitamin $\mathrm{D}$, retinopathy, and hearing impairment among T2DM. Vitamin D deficiency is an independent risk factor for diabetic retinopathy and hearing loss among diabetic patients. Meanwhile, hyperglycemia could be considered as a modifiable risk factor for diabetic retinopathy; tight glycemic control may be the most effective and important therapy for improving quality of life and substantially reducing the incidence of retinopathy and in T2DM patients.

\section{Data Availability}

The data used to support the findings of this study are available from the corresponding author upon request.

\section{Conflicts of Interest}

The authors declare that they have no conflicts of interest.

\section{Authors' Contributions}

Abdulbari Bener designed and supervised the study and was involved in data collection, statistical analysis, and the writing of the paper. Mustafa Eliaçık, Hakan Cincik, and Mustafa Öztürk were involved in data collection, interpretation of data, and writing of manuscript. Muhammad Abdul-Ghani and Ralph A. DeFronzo reviewed and revised the manuscript. All authors approved the final version.

\section{Acknowledgments}

This work was supported by the Istanbul Medipol University, International School of Medicine. The authors would like to thank the Istanbul Medipol University for their support and ethical approval (Research Protool and IRB no. 10840098604.01.01-E.3193).

\section{References}

[1] A. Bener, L. Hanoglu, H. Cincik, and M. Öztürk, "Is neuropathy and hypertensionassociated with increased risk of hearing loss among type 2 diabetic patients?" International Journal of Behavioral Sciences, vol. 1, no. 2, pp. 41-46, 2017.

[2] International Diabetes Federation, IDF Diabetes Atlas, vol. 166, IDF, Chaussee de La Hulpe B-1170 Brussels, Belgium, 6th edition, 2014.

[3] American Diabetes Association, "Classification and diagnosis of diabetes: standards of medical care in diabetes-2018," Diabetes Care, vol. 41, supplement 1, pp. S13-S27, 2018.

[4] A. Bener, F. E. Keskin, E. M. Kurtuluş et al., "Essential parameters and risk factors of the patients for diabetes care and treatment diabetes \& metabolic syndrome," Diabetology \& Metabolic Syndrome, vol. 6, pp. S1871-S4021, 2017.

[5] A. Bener, A. O. Al-Hamaq, E. M. Kurtulus, W. K. Abdullatef, and M. Zirie, "The role of vitamin D, obesity and physical exercise in regulation of glycemia in type 2 diabetes mellitus patients," Diabetes \& Metabolic Syndrome: Clinical Research \& Reviews, vol. 10, no. 4, pp. 198-204, 2016.

[6] A. Bener, A. O. Hamaq, K. Abdulhadi, A. H. Salahaldin, and L. Gansan, "The impact of metabolic syndrome and vitamin D on hearing loss in qatar," Otolaryngology, vol. 7, no. 3, pp. 1-6, 2017.

[7] S. Bonakdaran and N. Shoeibi, "Is there any correlation between vitamin D insufficiency and diabetic retinopathy?" International Journal of Ophthalmology, vol. 8, no. 2, pp. 326-331, 2015.

[8] E. Kurt, F. Öztürk, A. Günen et al., "Relationship of retinopathy and hearing loss in type 2 diabetes mellitus," Annals of Ophthalmology, vol. 34, no. 3, pp. 216-222, 2002.

[9] C. Ooley, W. Jun, K. Le et al., "Correlational study of diabetic retinopathy and hearing loss," Optometry and Vision Science, vol. 94, no. 3, pp. 339-344, 2017.

[10] H. Kaur, K. C. Donaghue, A. K. Chan et al., "Vitamin D deficiency is associated with retinopathy in children and adolescents with type 1 diabetes," Diabetes Care, vol. 34, no. 6, pp. 1400-1402, 2011.

[11] M. Santoshi Kumari and K. R. Meganadh, "Prevalence of otological disorders in diabetic cases with hearing loss," Journal of Diabetes \& Metabolism, vol. 07, no. 04, 2016.

[12] P. A. Patrick, P. F. Visintainer, Q. Shi, I. A. Weiss, and D. A. Brand, "Vitamin D and retinopathy in adults with diabetes mellitus," JAMA Ophtalmology, vol. 130, no. 6, pp. 756-760, 2012.

[13] H. Aksoy, F. Akçay, N. Kurtul, O. Baykal, and B. Avci, "Serum 1,25 dihydroxy vitamin $\mathrm{D}\left(1,25(\mathrm{OH})_{2} \mathrm{D}_{3}\right), 25$ hydroxy vitamin $\mathrm{D}(25(\mathrm{OH}) \mathrm{D})$ and parathormone levels in diabetic retinopathy," Clinical Biochemistry, vol. 33, no. 1, pp. 47-51, 2000.

[14] R. He, J. Shen, F. Liu et al., "Vitamin D deficiency increases the risk of retinopathy in Chinese patients with Type 2 diabetes," Diabetic Medicine, vol. 31, no. 12, pp. 1657-1664, 2014.

[15] J. F. Payne, R. Ray, D. G. Watson et al., "Vitamin D insufficiency in diabetic retinopathy," Endocrine Practice, vol. 18, no. 2, pp. 185-193, 2012.

[16] A. Bener, A. O. A. A. A. K. Al-Hamaq, A. H. Salahaldin, and L. Gansan, "Interaction between diabetes mellitus and hypertension on risk of hearing loss in highly endogamous population," Clinical Research \& Reviews, vol. 5, pp. S1871S4021, 2016.

[17] E. P. U. Helzner and K. J. Contrera, "Type 2 diabetes and hearing impairment," Current Diabetes Reports, vol. 16, no. 1, p. 3, 2016. 
[18] J. A. Whitworth, World Health Organization, and International Society of Hypertension Writing Group, "2003 World Health Organization (WHO)/International Society of Hypertension (ISH) statement on management of hypertension," Journal of Hypertension, vol. 21, no. 11, pp. 1983-1992, 2003.

[19] G. B. Reddy, M. Sivaprasad, T. Shalini et al., "Plasma vitamin $\mathrm{D}$ status in patients with type 2 diabetes with and without retinopathy," Nutrition Journal, vol. 31, no. 7-8, pp. 959-963, 2015.

[20] D. A. Debonis and C. L. Donohue, Survey of Audiology: Fundamentals for Audiologists and Health Professionals, Allyn \& Bacon, 2nd edition, 2007.

[21] M. R. Jørgensex and N. H. Buch, "Studies on inner-ear function and cranial nerves in diabetics," Acta Oto-Laryngologica, vol. 53, no. 2-3, pp. 350-364, 2009.

[22] A. Praidou, M. Harris, D. Niakas, and G. Labiris, "Physical activity and its correlation to diabetic retinopathy," Journal of Diabetes and Its Complications, vol. 31, no. 2, pp. 456-461, 2017. 


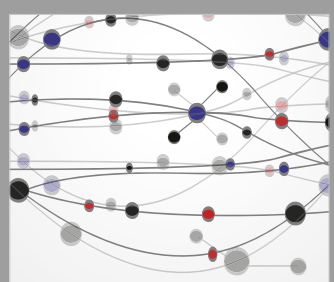

The Scientific World Journal
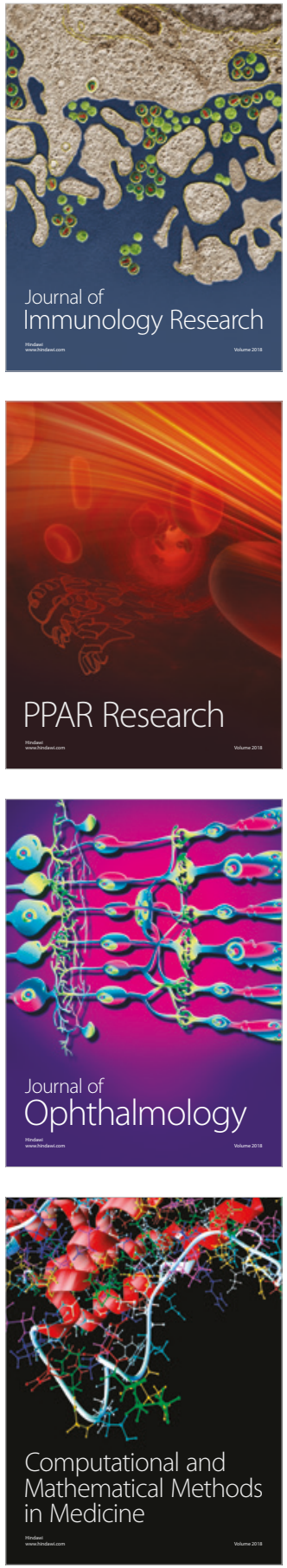

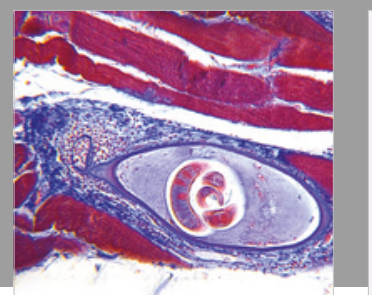

Gastroenterology Research and Practice

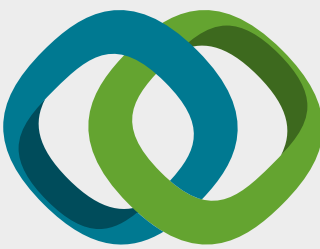

\section{Hindawi}

Submit your manuscripts at

www.hindawi.com
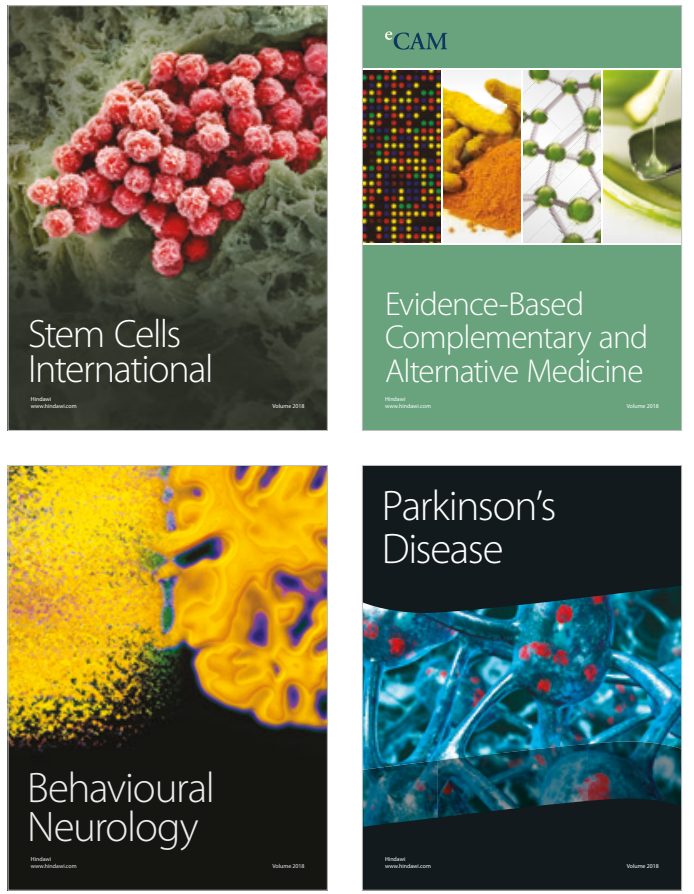

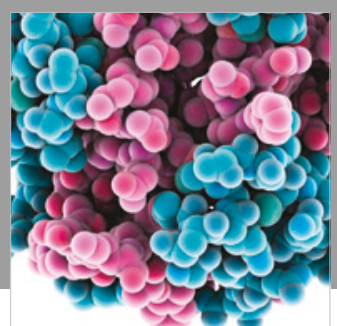

ournal of

Diabetes Research

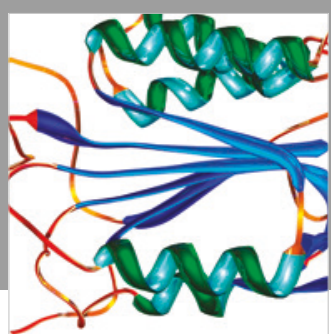

Disease Markers
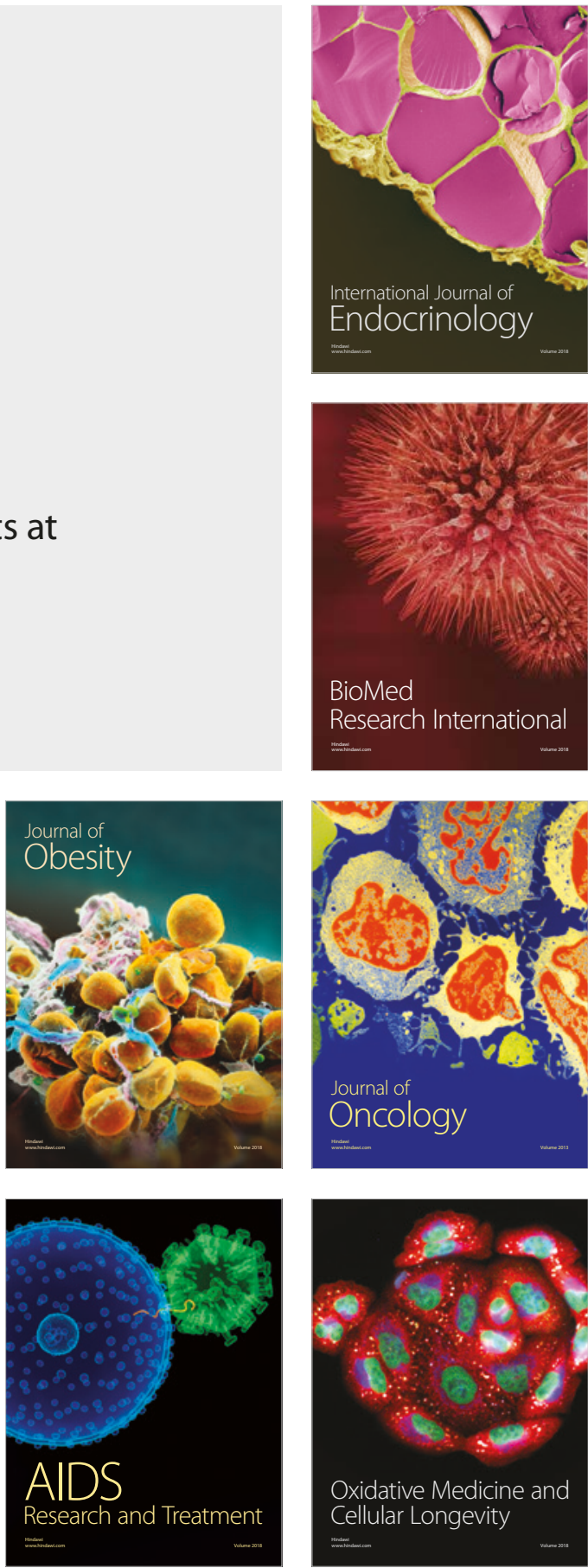